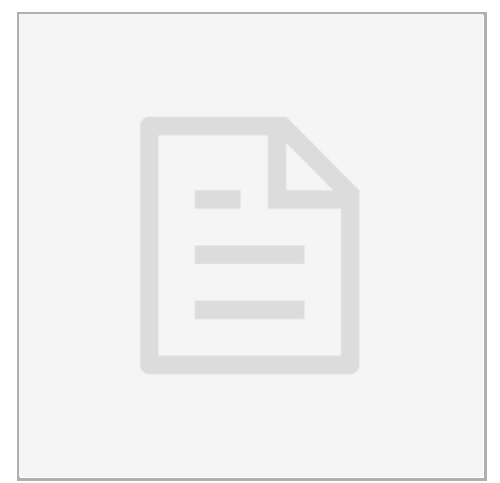

AUG 14, 2020

\title{
(3) Immunoblot analyses for investigating SpLG-binding to purified mammalian and avian immunoglobulins.
}

\author{
Angel A Justiz-Vaillant ${ }^{1}$
}

${ }^{1}$ University of the West Indies St. Augustine

University of the West Indies angel.vaillant@sta.uwi.edu

Angel A Justiz-Vaillant

University of the West Indies St. Augustine

\section{OPEN $\odot$ ACCESS}

\section{DOI:}

dx.doi.org/10.17504/protocol s.io. bjrukm6w

Protocol Citation: Angel A Justiz-Vaillant 2020.

Immunoblot analyses for investigating SpLG-binding to purified mammalian and avian immunoglobulins..

\section{protocols. io}

https://dx.doi.org/10.17504/p rotocols. io. bjrukm6w

License: This is an open access protocol distributed under the terms of the Creative Commons Attribution License, which permits unrestricted use, distribution, and reproduction in any medium, provided the original author and source are credited

Protocol status: Working We use this protocol and it's working

Created: Aug 14, 2020

Last Modified: Aug 14, 2020

\section{PROTOCOL integer ID:} 40468

1 Aliquots of egg yolks, sera or $2 \mu \mathrm{g} / \mu \mathrm{l}$ of purified immunoglobulins from birds, laboratory, wild, farm animals and pets are applied to the gels of SDS-PAGE as described elsewhere. 
2 Gels are transferred to nitrocellulose membranes (Immobilon-Nc, pore size $0.45 \mu \mathrm{m}$, SigmaAldrich Co, St Louis, Missouri) during 75 minutes at 40 mAmps using a semi-dry electroblotter, HEP-1 Model, Owl Scientific Inc.

3 The running buffer contains $25 \mathrm{mM}$ Tris, $192 \mathrm{mM}$ glycine $\mathrm{pH} 8.3$ and $20 \%$ methanol.

4 The nitrocellulose membranes are blocked overnight in $10 \%$ non-fat skim milk in PBS with $0.05 \%$ Tween-20 pH 7.4 and then washed 4x, 10 minutes with PBS-Tween 20.

5 Recombinant protein $L G$ or a mixture of $S p L$ and $S p G$ at a concentration of $5 \mu \mathrm{g} / \mathrm{ml}$ is added to the membranes.

6 After that there is an incubation period at $4^{\circ} \mathrm{C}$ overnight.

7 The nitrocellulose membranes were washed as above.

8 A secondary antibody (rabbit anti-chicken IgY horseradish peroxidase, Sigma Aldrich) is added at a 1:15 000 dilution.

9 It is incubated for one hour at room temperature and washed as above. 
10 Tetramethyl-benzidine (TMB) solution is added to the nitrocellulose membranes, which are then incubated in the dark for seven minutes. Then, the membranes are shaken gently and rinsed thoroughly in de-ionized water to stop the blotting process and are left to dry.

11 Alternatively, Ig samples are transferred to nitrocellulose membranes and directly probed using SpLG-HRP (diluted 1:5000) and TMB (this system was mainly used for detecting avian Igs). 